\title{
Een integrale aanpak van preventie vraagt om een sterke verbinding met de eerste lijn
}

\author{
Gerard R. M. Molleman · W. J. J. (Pim) Assendelft · Maria E. T. C. van den Muijsenbergh · L. A. M. (len) van de Goor
}

Published online: 19 February 2019

(C) The Author(s) 2019

Sinds het Ottawa Charter van de WHO uit 1986 wordt er al gepleit voor een integrale aanpak van gezondheidsvraagstukken als we een rechtvaardig en effectief gezondheidsbeleid willen realiseren [1]. Uit het oogpunt van rechtvaardigheid moeten de gezondheidsverschillen worden opgeheven. Tegelijkertijd weten we dat gezondheidsverschillen hardnekkig zijn en moeilijk zijn op te lossen [2]. Het vraagt om politieke keuzen en is nadrukkelijk een verantwoordelijkheid van alle maatschappelijke sectoren, en niet alleen van de gezondheidszorgsector. Een integrale aanpak vergt volgens het Ottawa Charter een gezondheidsbeleid waarin aandacht is voor een gezonde sociale en fysieke omgeving, participatie, focus op empowerment van de burgers en samenwerking tussen de curatieve en preventieve sector. Voor dit laatste aspect is een sterke eerstelijnsgezondheidszorg cruciaal. Deze brede benadering heeft in 2019 nog niets aan actualiteit ingeboet. Sterker nog: tijdens de jongste WHObijeenkomst in Astana eind 2018 werd zij door alle lidstaten bevestigd. In het door Pharos ondersteunde 'Gezond in ...'--programma, dat de lokale aanpak van gezondheidsachterstanden in GIDS-gemeenten stimuleert, zien we dit gedachtegoed naadloos terug in

Prof. dr. G. R. M. Molleman (凶) •

Prof. dr. W. J. J. (Pim) Assendelft · Prof.dr. M. E. T. C. van den Muijsenbergh

Eerstelijnsgeneeskunde, Radboudumc, Nijmegen, Nederland

gerard.molleman@radboudumc.nl

Prof. dr. G. R. M. Molleman

GGD Gelderland Zuid, Nijmegen, Nederland

Prof.dr. M. E. T. C. van den Muijsenbergh

Pharos, Utrecht, Nederland

Prof. dr. L. A. M. (Ien) van de Goor

Tranzo, Tilburg University, Tilburg, Nederland de vijf sporen en acht pijlers, die als uitgangspunt voor dit programma worden gegeven [3].

Vanuit het perspectief van gezondheidsbevordering is het spoor waarin de samenwerking tussen preventie en zorg wordt bepleit relatief het minst uitgewerkt. Dat heeft niet te maken met het belang dat aan deze samenwerking wordt gehecht: beleidsmakers en gezondheidsbevorderaars wijzen al jaren op de potentie voor gezondheidsbevordering van deze samenwerking. De curatieve sector, en zeker de eerste lijn, ziet dagelijks de mensen met chronische aandoeningen bij wie leefstijlaspecten een belangrijke rol spelen. En we weten dat roken, overgewicht en te weinig bewegen beduidend meer voorkomen bij mensen met een lage SES dan bij mensen met een hoge SES [4]. Mensen met een lage SES komen bovengemiddeld vaak met gezondheidsklachten bij de huisarts. Die is daarmee een ideale 'vindplaats'. Dat biedt voor de huisarts als gezins- en levenslooparts goede ingangen voor in het bijzonder selectieve preventie en het aanspreken en motiveren van mensen om hun leefstijl te verbeteren.

In de praktijk van de eerste lijn blijkt dat vaak helemaal niet zo makkelijk. De afstand tot de publieke gezondheid en de gezondheidsbevorderende taken van de GGD is vaak groot. De circuits zijn relatief gescheiden en men spreekt niet dezelfde taal. De dominantie van de individueel gerichte geneeskunde maakt een meer collectieve en integrale aanpak niet vanzelfsprekend. En aan de andere kant hebben collectieve leefstijlprogramma's vaak geen aandacht voor contextuele factoren die gezond gedrag belemmeren. De verschillen in financiering van de zorg door de zorgverzekeraars en de publieke gezondheid door de gemeente geven ook niet de juiste prikkels om samen te werken. 


\section{Meer en beter samenwerken}

Er is kortom een wereld te winnen voor de publieke gezondheid en de curatieve sector als we meer en beter kunnen samenwerken aan het verbeteren van de gezondheid van de bevolking. En als preventie in de zorg zo logisch lijkt, waarom gebeurt het nog steeds te weinig? Gelukkig zien we in de curatieve sector steeds meer aandacht voor preventie: in de toekomstvisies van beroepsverenigingen, preventie- en zorgakkoorden, preventiecoalities, de Gecombineerde Leefstijlinterventie en de opmars van e-health. Waar preventie van oudsher tot het domein van de publieke gezondheidszorg hoort, is de 'curatieve sector' zich steeds meer bewust van zijn mogelijkheden en verantwoordelijkheden om niet alleen ziekte te genezen, maar vooral ook te voorkomen. Maar weten we wel voldoende over wat er vooral in de curatieve sector gebeurt?

Bovenstaande is de reden om een themanummer over preventie in de eerstelijnszorg uit te brengen en daarvoor een speciale gastredactie uit beide domeinen samen te stellen.

\section{Een nieuwe tijd}

In dit nummer belichten experts vanuit hun zeer diverse achtergronden het onderwerp preventie in de zorg. Aan bod komt zowel de organisatie van preventie - de rolopvattingen van professionals, de noodzaak tot domeinoverstijgende samenwerking, financiering, de belofte van e-health -, als de inhoud van preventie - moeilijk bereikbare groepen, individu versus groep, lokaal versus landelijk. Ook het internationale perspectief komt aanbod.

Al met al zien wij een nieuwe tijd gloren, met meer ruimte voor preventie in de zorg. Dat wordt ook weerspiegeld in het onlangs afgesloten Preventieakkoord, en ook in de rol van preventie in de in 2018 afgesloten Zorgakkoorden voor huisartsen en de ziekenhuizen. Weliswaar is preventie 'van oudsher' een publieke gezondheidstaak en daarom een kernthema in
TSG, maar steeds duidelijker wordt dat ook de curatieve sector, en dan vooral de eerste lijn, een belangrijke rol kan spelen bij preventie. Daar mag in TSG meer aandacht aan geschonken worden.

\section{Investeren}

Het maatschappelijk belang om meer aan preventie te doen neemt alleen maar toe. Een gezondere leefstijl kan de toename van chronische aandoeningen terugdringen en daarmee het aantal gezonde levensjaren en de kwaliteit van leven voor álle groepen verbeteren. Om een gezonde leefstijl te bevorderen is het cruciaal om een optimale verbinding en samenwerking tussen eerstelijnszorg en publieke gezondheid te realiseren. Investeren in deze samenwerking draagt bij aan het terugdringen van zorguitgaven. De huidige hoge zorguitgaven verdringen investeringen in andere maatschappelijke sectoren, zoals onderwijs, participatie en arbeidsmarktbeleid. Deze gebieden kunnen helpen om een verdere tweedeling te verkleinen en daarmee bij te dragen aan het verminderen van gezondheidsverschillen.

Open Access This article is distributed under the terms of the Creative Commons Attribution 4.0 International License (http://creativecommons.org/licenses/by/4.0/), which permits unrestricted use, distribution, and reproduction in any medium, provided you give appropriate credit to the original author(s) and the source, provide a link to the Creative Commons license, and indicate if changes were made.

\section{Literatuur}

1. World Health Organisation. Ottawa charter for health promotion. New York: WHO; 1986.

2. Wetenschappelijke Raad voor het Regeringsbeleid (WRR). Van verschil naar potentieel. Een realistisch perspectief op de sociaaleconomische gezondheidsverschillen. Den Haag: WRR;2018.

3. Gezond in...https://www.gezondin.nu. Geraadpleegd op 23 november 2018.

4. RIVM. Volksgezondheidstoekomstverkenning 2018. Bilthoven: RIVM; 2018. 